\title{
UN RETRATO DE DOÑA LEONA VICARIO A LOS CINCO AÑOS*
}

Marita Martínez Det Río

Sobre un muro del cubo de la escalera que conduce al claustro superior en la clausura del Convento de las Carmelitas Descalzas en la Calle de la Rondilla de Santa Teresa, en Valladolid, España, se distingue en la silente penumbra, un cuadro de grandes proporciones. En él se representa a un grupo de personas que posa en una habitación amplia con un gran ventanal enmarcado por un cortinaje encarnado. Se trata de don Gaspar Martín Vicario y de su hermosa familia compuesta únicamente de mujeres. A su ladơ está su segunda esposa, doña Camila Fernández de San Salvador, sus hijas doña María Luisa y doña María Brígida, nacidas de sus primeras nupcias con doña Petra Elías, y la más pequeña, doña María Leona, hija de doña Camila. El cuadro lleva al pie la inscripción: "Verdaderos retratos de D. Gaspar Martín Vicario, natural de la Villa de Ampudia en Castilla la Vieja: familiar del Santo Tribunal de'la Inquisición de la Ciudad de México, Regidor Onorario y Diputado del común que ha sido de dicha Ciudad; y Diputado actual del Real Tribunal del Consulado de ella su edad 50. años y 9.meses. De doña Camila Fernández de San Salvador su lexítima muger en segundas nupzias su edad 30 años 6 . meses; y de doña María Luisa su edad 10. años doña María Brígida su edad 8. años doña María Leona su edad 5. años; las dos primeras hijas del referido don Gaspar y de doña Petra Elías Beltrán su lexítima muger en primeras nupzias; y la tercera hija de los expresados don Gaspar y doña Camila. Diciembre 29 de 1793. Domingo Ortiz lo pintó en México". El cuadro mide $1.94 \mathrm{~m}$ de largo por 2 de alto; en buen estado de conservaci6n, ciertas líneas indican dobleces o añadidos deficientes.

Califica don Manuel Toussaint ${ }^{1}$ como "mediocre artífice" a Domingo Ortiz, cuyas poquísimas obras conocidas se encuentran, una de

* A la Reverenda Madre María Capilla de Jesús, Carmelita Descalza, dedico este pequeño estudio del cuadro que se conserva en el Convento del cual ella es la Priora. A Jesús Urrea Fernández agradezco las fotografías.

1 Manuel, Toussaint. Pintura colonial en México, edición de Xaviex Moyssén, México, UNAM, Instituto de Investigaciones Estéticas, Imprenta Universitaria, 1965, página 177 
ellas en la capilla de San Antonio, en San Juanico, barrio en las inmediaciones de Tacuba: representa una Conversión de San Agustín de regular factura y en la Santa Veracruz, una bonita imagen de Nuestra Señora de Guadalupe firmada en 1796. En el retrato de la familia de don Gaspar Martín Vicario, sin duda alguna Ortiz puede considerarse como medianamente buen retratista. La composición es agradable aunque convencional e ingenua, mas no carente de elegancia lograda por la prestancia de don Gaspar, la belleza de los rostros femeninos y los vaporosos atuendos. Aquí no encontramos las perlas, los diamantes, los relojes, los brocados, las plumas y los chiquiadores, las veneras, las bandas y las condecoraciones que proliferan en los retratos dieciochescos de la nobleza novohispana dándoles valor artístico y decorativo. En éste, las flores son el único adorno, y el toque exótico lo da el plátano que lleva doña María Brígida en la mano. El colorido a base de tonos pálidos muy diluidos aligeran el conjunto, escogidos acertadamente por el artista dado el gran tamaño de su obra, restándole así: solemnidad y pesantez. El cuadro en sí es además una imagen representativa de la época, ya que implícitamente figuran en ella tres grupos de la clasificación social o étnica contemporánea denominada castas. Don Gaspar, nacido en España es peninsular; doña Camila, hija de padres nacidos en Nueva España, mexicana; las hijas, de padre peninsular y madre mexicana, criollas.

El rostro de don Gaspar acusa su origen castellano de pura cepa: alargado, enjuto, con nobles facciones, nariz fuerte, boca delgada y firme, ojos cubiertos en parte por párpados oblículos bajo las cejas pobladas y varoniles. El pelo blanco natural, sin peluca ni polvos, atado simplemente con un lazo negro en la nuca. Doña Camila, representa a la joven que contrae matrimonio con el viudo peninsular, rico y prominente, no carente de atractivo, aunque mucho más viejo. Su rostro, redondo y agradable, con grandes ojos negros, la mirada expresiva bajo la bien delineada ceja. En el extremo izquierdo, la primogénita, doña María Luisa, expresa placidez y madurez poco comunes a la edad de diez años, cuando la pintó Ortiz; posiblemente éste captó algo de la tristeza de una huérfana. Su digno porte seguramente haría honor al título de nobleza que ostentaría durante su matrimonio, ocho años después. Doña María Brígida - -la segunda hija de don Gaspar y de doña Petra Elías; tiene los ojos oscuros y meditabundos. La pequeña doña María Leona, posee como su padre, el rostro que demuestra 
más personalidad: aun ignorando el importante papel que desempenaría más tarde, atrae por la fuerza que se adivina en su carita de niña. La boca enseña cierta obstinación, señalada por un ligero sombrero alrededor, que le da cierta arqueada protuberancia. La nariz parece respingona, los ojos muy separados con una mirada decidida e inteligente. De Leona escribiría más tarde Carlos María de Bustamante que "la naturaleza no le había negado un personal airoso y distinguido"2 y Jacobo María Sánchez de la Barquera la describe ya madura: "rostro lleno, afable y sonrosado, frente ancha, alta y vertical: cejas muy delgadas; ojos grandes, negros, de mirar luminoso, firme y enérgico, nariz fina y correcta y boca pequeña y sonriente", ${ }^{3}$ descripción que parece confirmada en el retrato: los rasgos plasmados por Ortiz no sufrirían mayor alteración que la causada por los años.

Los atuendos de la familia Vicario dan al cuadro armonía y luz: los tres tonos de azul del lado derecho y las tres gamas de rosa en el izquierdo que resaltan contra el cortinaje encarnado. Viste don Gaspar casaca y alzas de paño azul oscuro adornados con galón de oro, medias de seda blancas y chapines con gran hebilla dorada. La chupa blanca también bordada, la botonadura de oro, el plastrón con chorrera de hilo fino y mangas que sobresalen de los puños vueltos muy bordados. No lleva ningún reloj, venera o banda y únicamente tiende a su pequeña hija Leona una moneda; ésta levanta la mano con un aire distraído mirando hacia el artista. Don Gaspar se apoya en una mesa con cubierta de mármol. El vestido de doña Camila se del tono llamado "azulón" en Castilla; lo rematan dos volantes y se asoma parte del panier terminado con olán blanco haciendo juego con la falda. Se cubre con pañoleta o mantellina de gasa adornada con rosas. Entre los dedos de la mano izquierda sostiene delicadamente una rosa, a la manera del retrato de la reina María Antonieta, de Mme. Vigée Lebrun. En la derecha, el indispensable abanico.

Doña María Luisa está vestida con muselina bordada ligeramente de ramos y espigas. Como su madrastra, lleva panier, pañoleta también terminada con flores, un pañuelo en una mano y un abanico en la otra. Enmarca el rostro de ambas el anchísimo peinado ahuecado y

2 Carlos María de, Bustamante. Necrologia de la señora doña Leona Vicario de Quintana. México, E1 Siglo XIX, agosto, 1842.

a Jacobo Maria, Sánchez de la Barquera. La Patria Ilustrada, México, $1^{\circ}$ de oc. tubre, 1894. 
empolvado característico de la época. Los vestidos iguales de las medias hermanas doña María Brígida y doña María Leona, son aniñados, organza alforzada hasta media falda con el talle también cubierto por la pañoleta que se adorna con flores en la parte superior de la manga. Los peinados idénticos, rizados con una trencita sobre el fleco, podrian ser actuales. La niña mayor sostiene un plátano en una mano y un abanico en la otra, mientras que la pequeña sujeta una caja de costura o almohadilla. El grupo de mujeres tiene un cierto aire goyesco: los trajes vaporosos y veraniegos, los voluminosos peinados que enmarcan unas caras pequeñas, eran los que usaban algunas de las señoras que posaron para Goya.

Don Gaspar Martín Vicario, nacido en la Villa de Ampudia, coronada por su soberbio castillo, vino a Nueva España a hacer fortuna: con su trabajo e inteligencia poco común -que heredó su hija Leonahizo un capital considerable y alcanzó los títulos y honores mencionados al pie del cuadro. Como se dijo, a la muerte de doña Petra Elías Beltrán casó con doña Camila Fernández de San Salvador, nacida en Toluca, hija de don Casimiro, oriundo de Zacatecas y de doña Isabel Montiel. Una de las hijas de doña Petra, doña Maria Luisa, casó con don Antonio Guadalupe Vivanco, segundo marqués de Vivanco. Y a la muerte de éste, pocos años después, con Juan de Noriega: ${ }^{4}$ No se tienen noticias de la pensativa doña María Brígida, pero es lógico suponer que tomó el velo de la Orden de las Carmelitas Descalzas, dado que este retrato se conserva en dicho convento de Santa Teresa de Valladolid que, por cierto, fue una de las primeras fundaciones de la Santa de Ávila. Además, personas que en su niñez conocieron a monjas ya muy mayores, recuerdan que estas hablaban de "... una monjita mexicana..." que habia estado hacía ya muchos años en el convento. Curiosamente su nombre no aparece en los registros de la época, pero el convento conserva un terno de casullas bordadas en tisú de oro, del siglo xviır ,también regalo de la familia Vicario y, como es del conocimiento general tales obsequios obedecian generalmente a que algún miembro de la familia pertenecía a la comunidad religiosa que gozaba de ellos.

Doña María Leona nació el 10 de abril de 1789, poco después del

4 Doris M., Ladd. The Mexican Nobility at Independence, 1780-1826, USA, Ins titute of Latin American Studies, The University of Texas at Austin, 228. 
DOI: http://dx.doi.org/10.22201/iie.18703062e.1983.52.1194

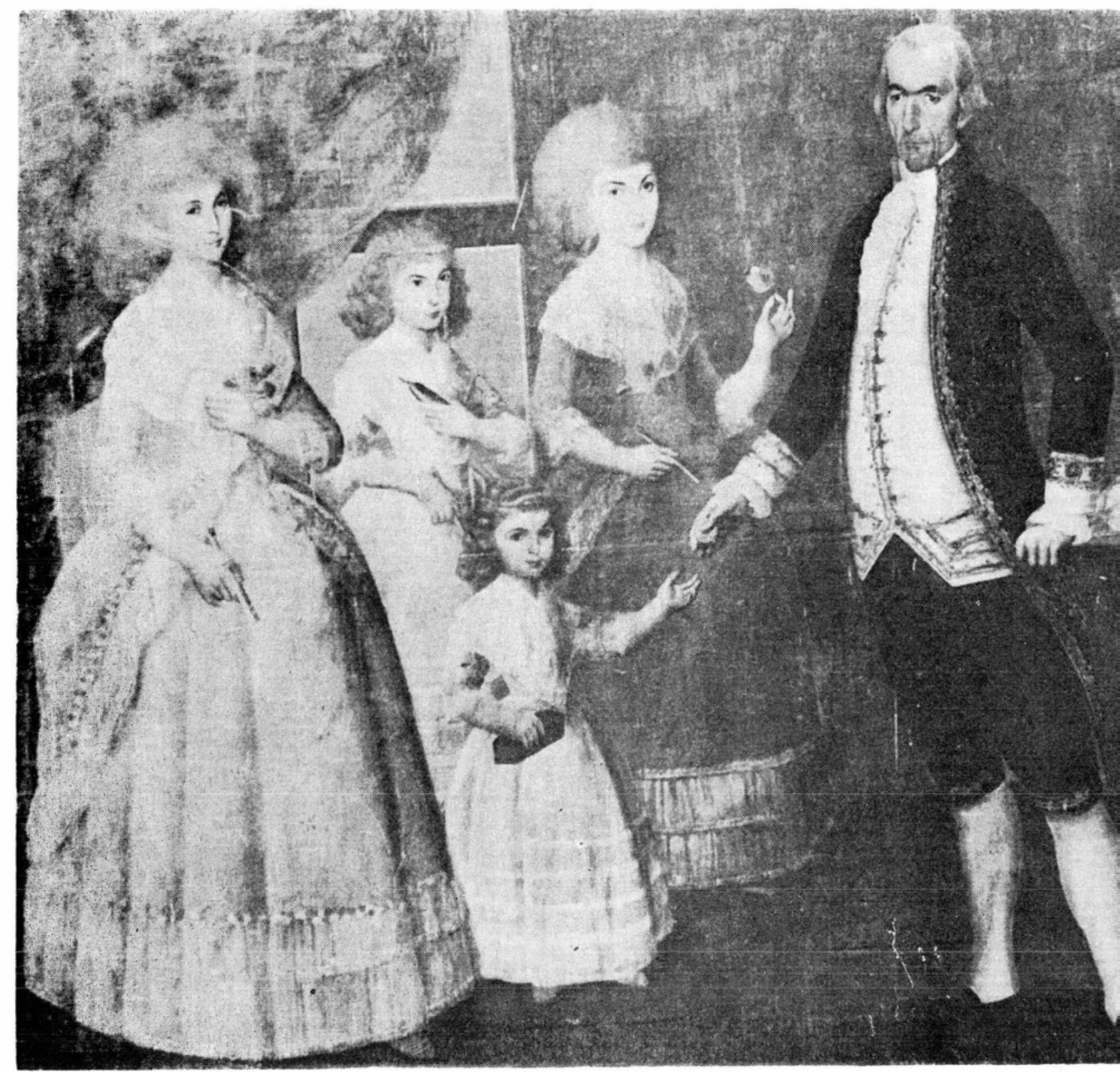

Figura 1. Domingo Ortiz. Gaspar Martin Vicario y su familia. 1793. 


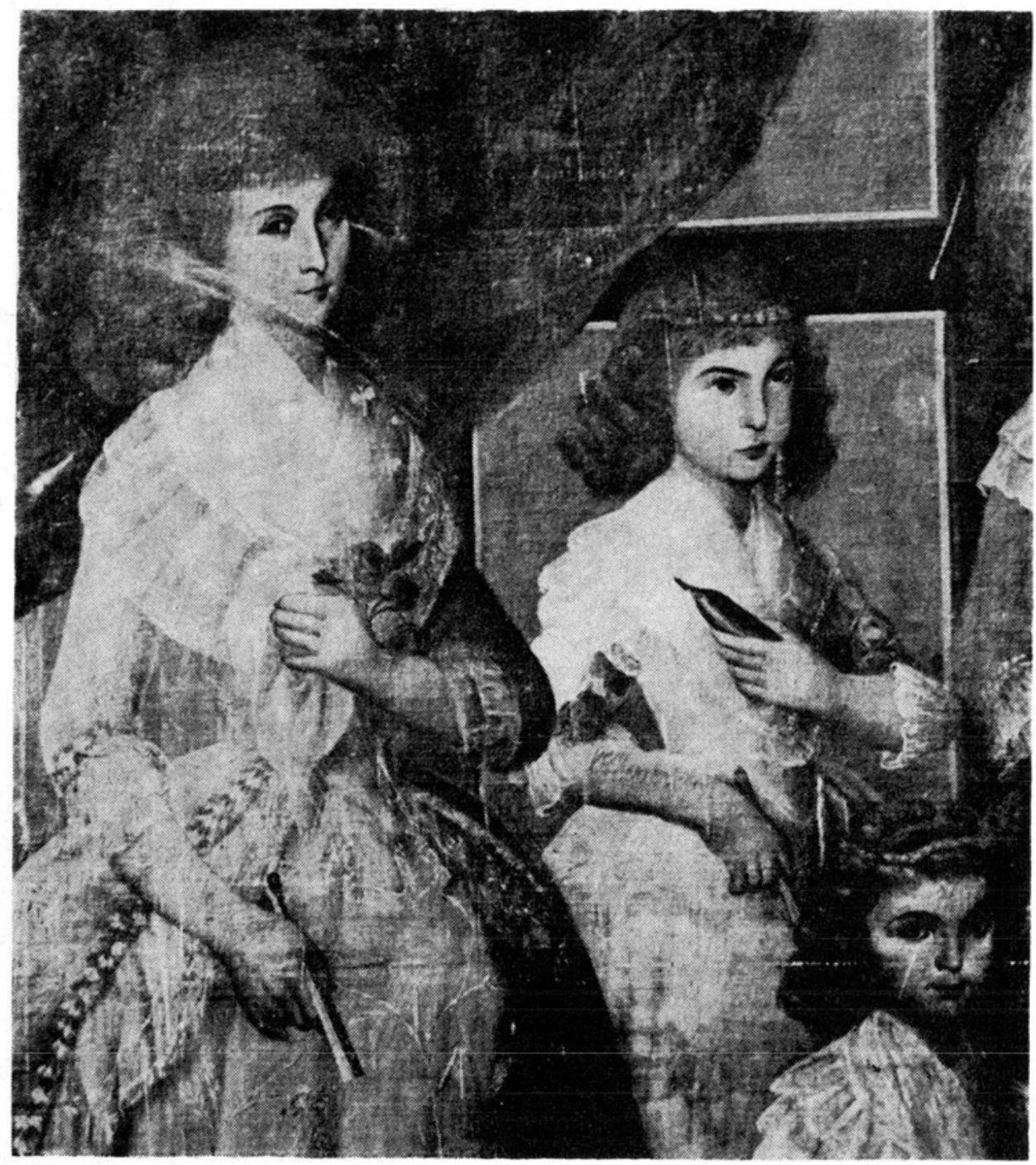

Figura 2. Domingo Ortiz. Las hijas de Gaspar Martin Vicario. Detalle. 
DOI: http://dx.doi.org/10.22201/iie.18703062e.1983.52.1194

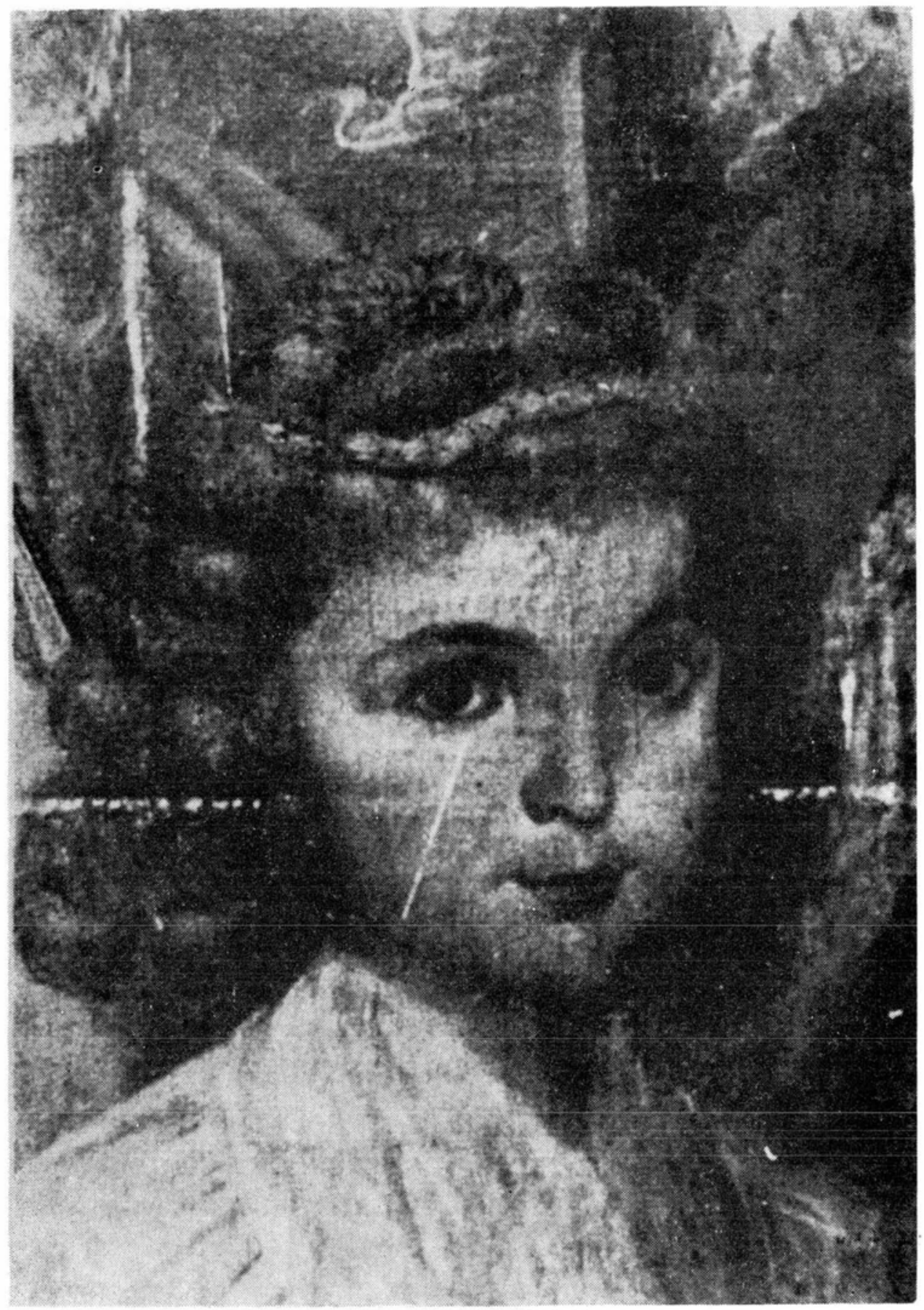

Figura 3. Domingo Ortiz. La niña Leona Vicario. Detalle. 
matrimonio de sus padres. ${ }^{5}$ A su orfandad, en 1809, su tío don Pomposo Fernández de San Salvador, actuando como su tutor, la instaló en una buena casa en la calle de Don Juan Manuel número 19, donde habitó rodeada de libros entre los que se encontraban las obras de Feijoo, La Place, Fenelon y algunos clásicos que eran sus lecturas favoritas, y servida por un batallón de criados. Casó en 1813 con don Andrés Quintana Roo, quien trabajaba para don Pomposo. Siempre devota de Nuestra Señora, a su muerte, en 1842, dejó a los santuarios de Los Remedios y a la Colegiata de Nuestra Señora de Guadalupe, sumas considerables El inventario de sus bienes confirma una sólida posición económica. ${ }^{6}$ De ella escribía don Lucas Alamán hacia los finales de su azarosa vida: “... si M. Stael atribuye algunas de las acciones de patriotismo en las mugeres (sic) a la pasión amorosa, esto no probará jamás que sean incapaces de ser patriotas cuando el amor no las estimula a que lo sean". Como parece confirmarlo su encantador aspecto de niña, sería doña María Leona, años después: "el ornamento de su secso (sic) y la gloria de su patria".7

5 Genaro, García. Leona Vicario. Heroina insturgente, $1^{\text {a }}$ ed., 1910, vetsión de 1979, México, Editorial Innovación, S.A., 1929.

6 Ibid. p. 20.

7 Bustamante, ob. cit. 